\title{
人数然雜嚲 44.7
}

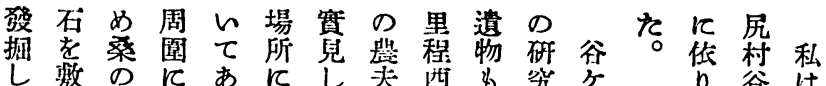
し媻 植多 る

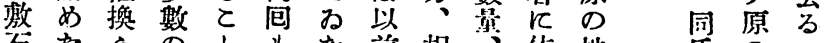

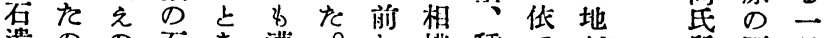
遗のの石を遭。出模程て が 所石月 跡を第を礁遇就方川類大遭有器十 は㻐、環めし中耕山實分物畑時似

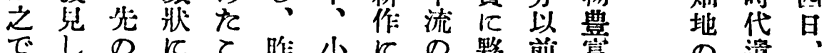

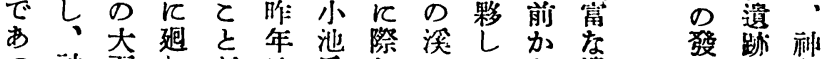
己萠不しがは氏

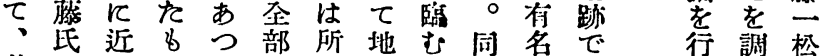

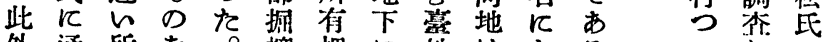
外通所を。据畑飞地はなる 同しをを挶文げ地不絰八つこ

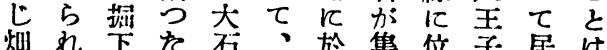
畑れ下た石、於集位手居は 他劣 のでああ心大石てて原探藤 場あるると體のおる䮨集氏 所 る 8 今 $\tau$ ᄂ

3 同㐫

の 地 で 敷 敷 小 相 石染全莫 跡产津 を氐久 兒の井 望 好. 郡

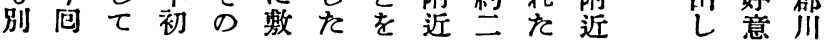

石

遺

跡

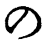

新

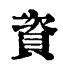

料

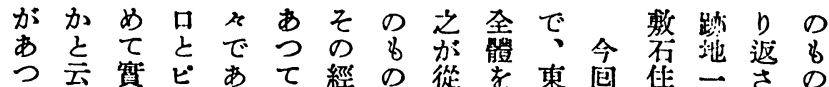

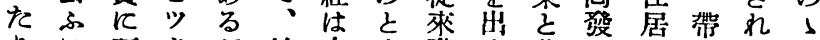

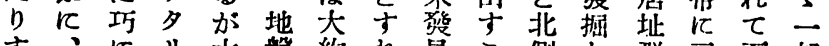
す、次大盤約れ胃と側し群亘石部

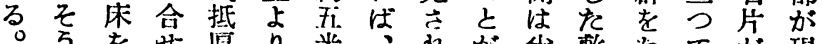

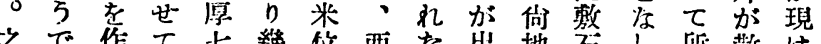

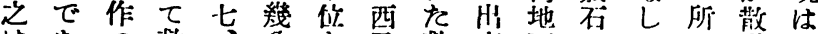

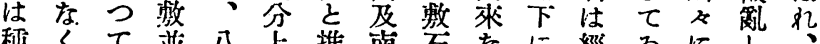
程くて並八吉推南石な心經るにし、

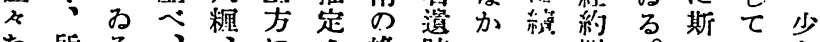

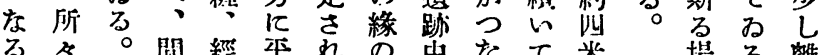

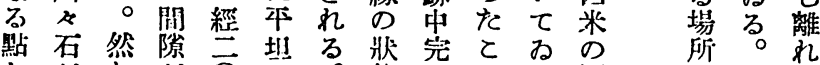

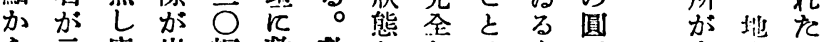

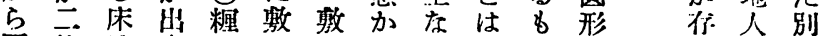

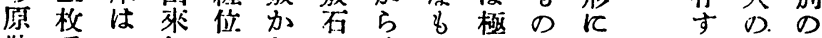

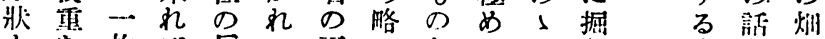

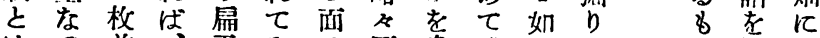

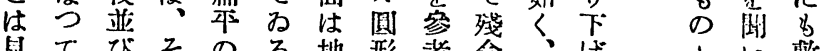

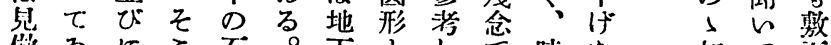

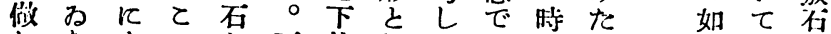

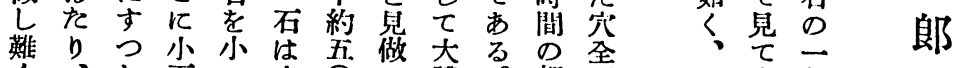

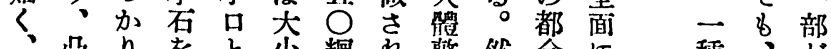

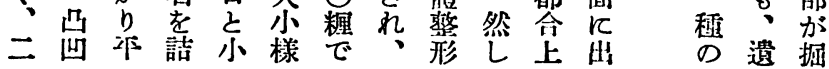

八

幡 $\Xi$
0 
昭和士分: 7 月
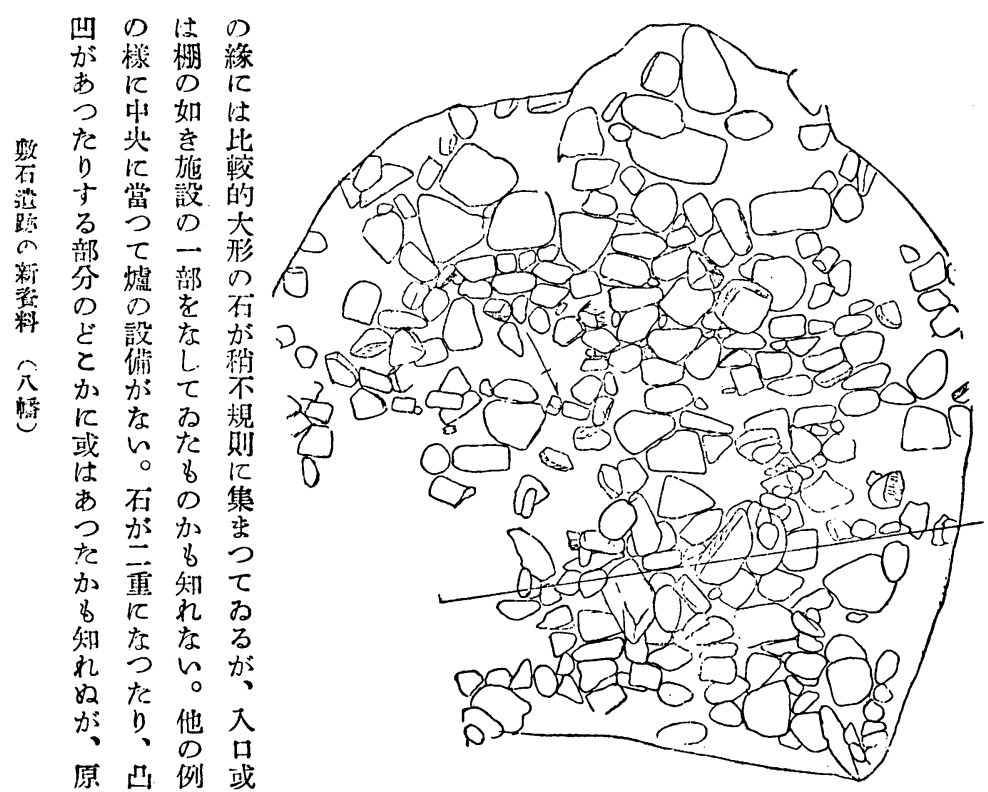

そ思枚

上れな

石凸て

加出乃

持のる

上あの

げるは

ら の 们

れ 福

た澍加

ら の

ᄂ 根 理

く出 由

才。石

$つ$ の 管

之下若

脉 $几<$

を张は

なつ移

ᄂ? 㓰

おそた

る

南学尔

物 圆 石 の 雜

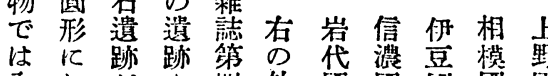

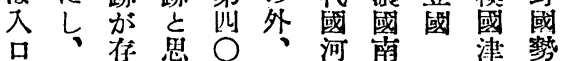

几中L经私沼佐多

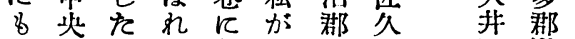

不・时、報筸河郡郡郡瀧

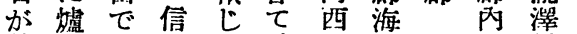

数を市浱た確村瀨鄉村

几設方國相筫等村村村

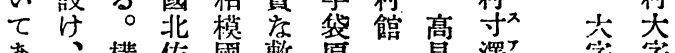

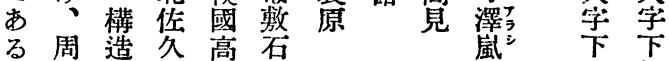

る周造久高石

三先分石悲郡跡

下嗃查要石棚

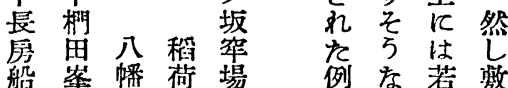

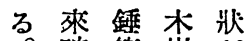

九記をる非名報

し高を村 村 せ

田堤本場 外

確等炭 方 顀 がの靴 なあ屑さ 數つかれ 石た散て 遺曻? 紫直な朋 ᄂ 接市方

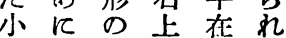
池し整元管る 氏 $\tau$ ○ 8 以 實 た亦如前 見る る の漂 文で方此類 形或は敷程學

を乭整

舉の の 面

る 别喾 所

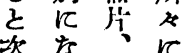

の品點

通了雌皮

b石之

で從石元 


\section{人数㸚雅站 44.7}

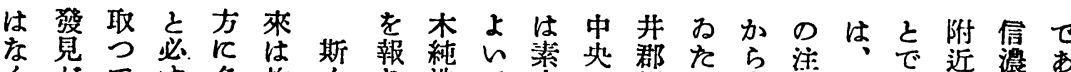

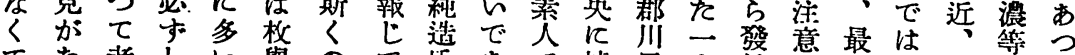
てな将しん藇のて此あで嘘尻人胃学初な多のた 竪。て

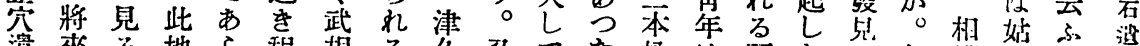

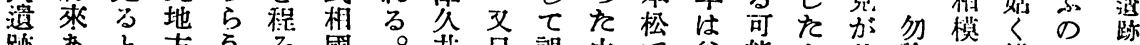

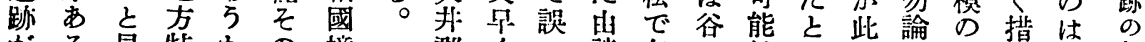

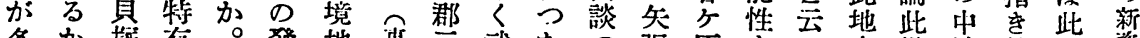

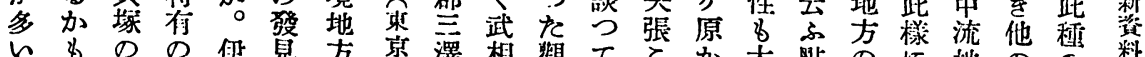

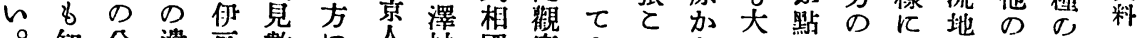

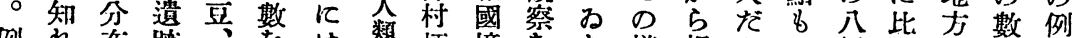

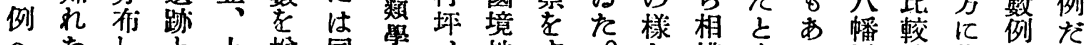

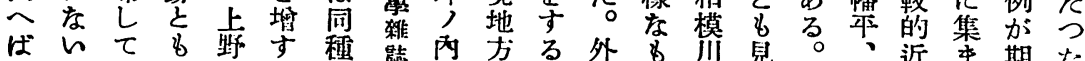
代 $几$ て

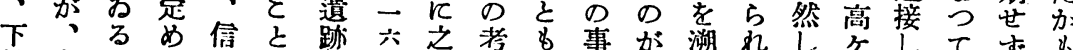

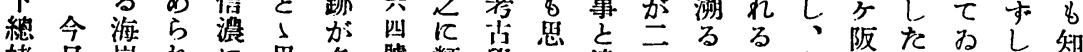

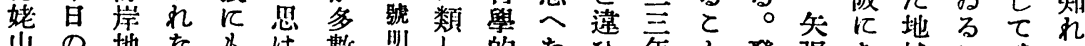

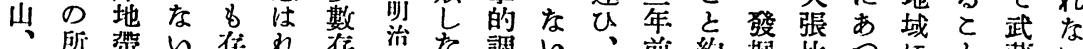

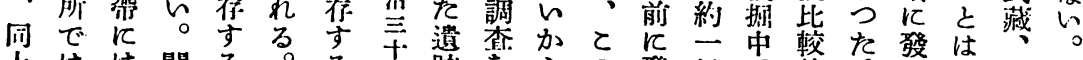

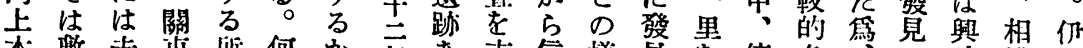

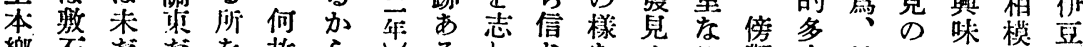

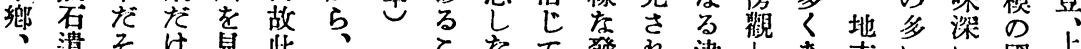

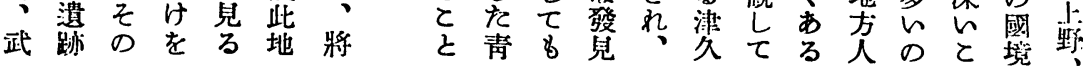

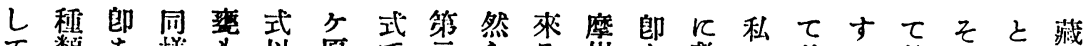

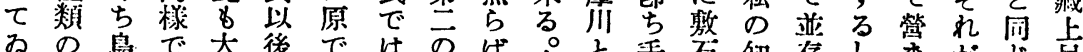

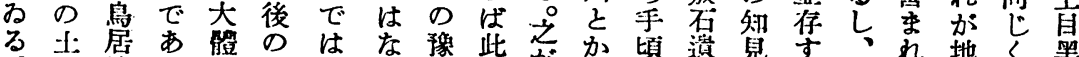

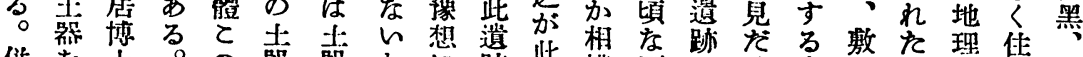

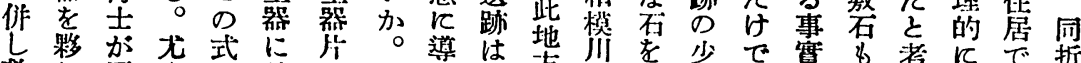

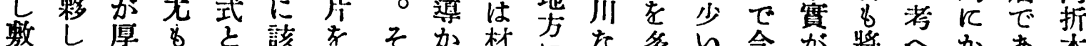

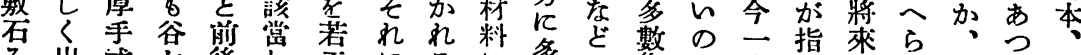

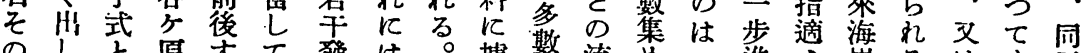

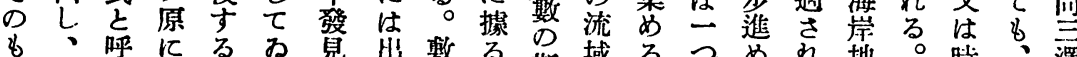

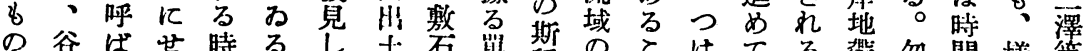

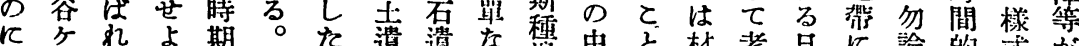

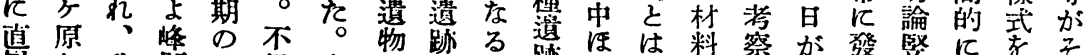

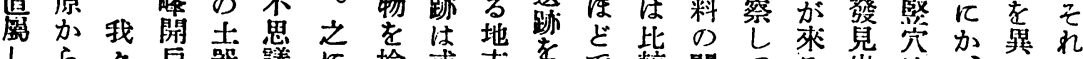

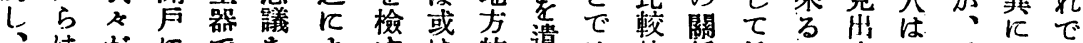

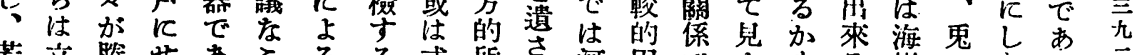

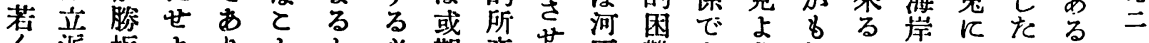

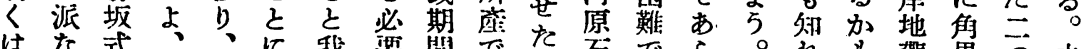

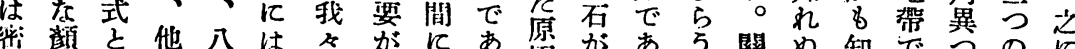

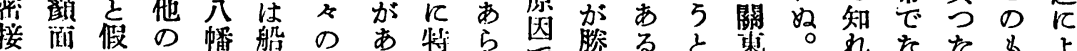

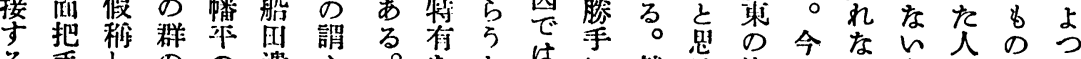

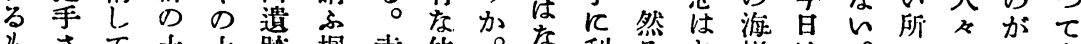

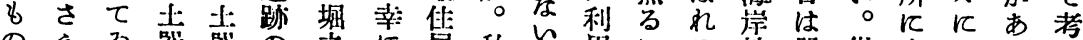

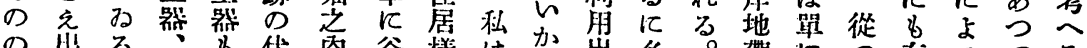

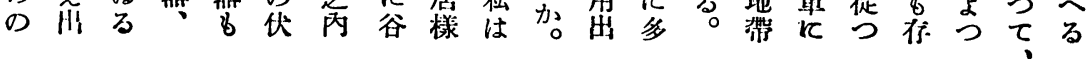


常か之谷後飞君なと當れでて私をの が時大

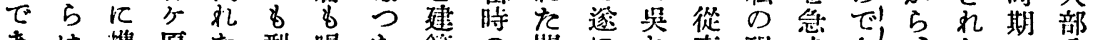

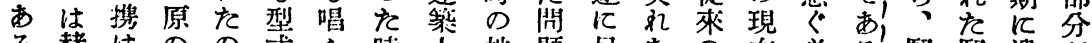

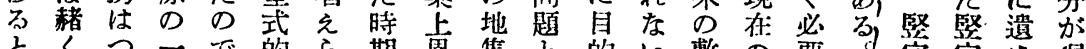

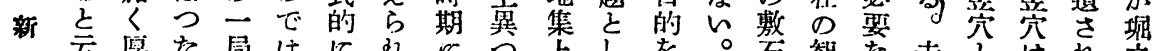

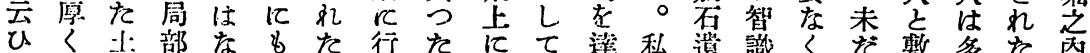

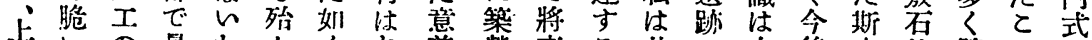

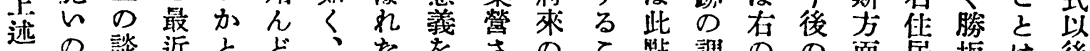

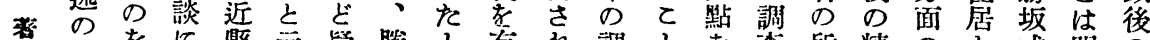

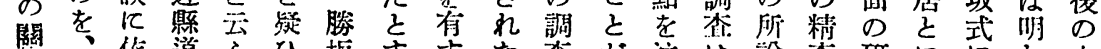

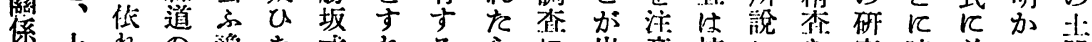

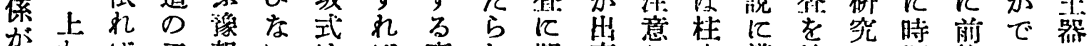

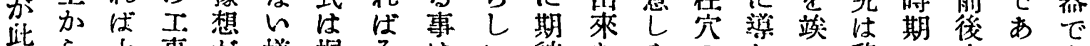

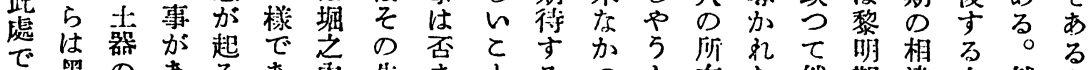

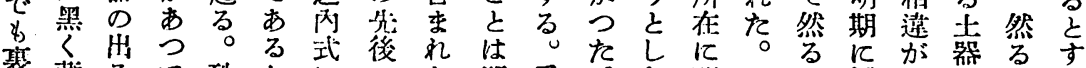

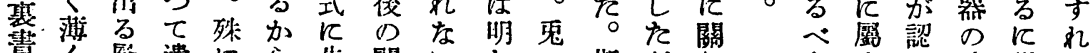

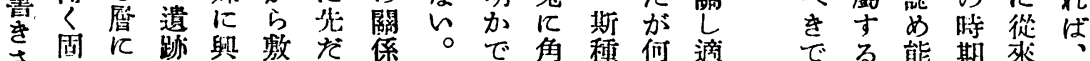

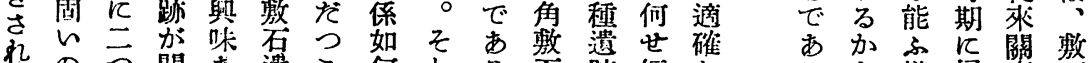

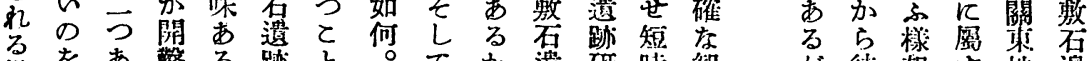

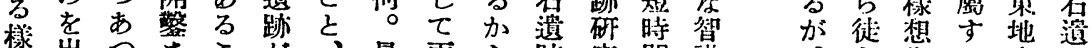

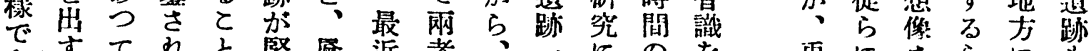

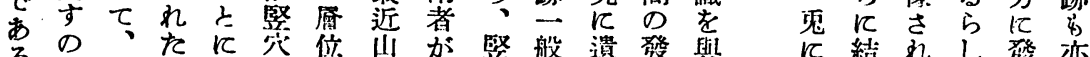

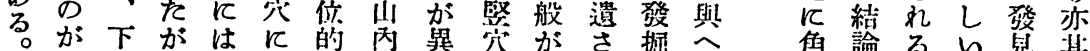

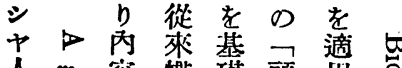

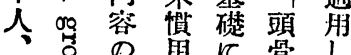

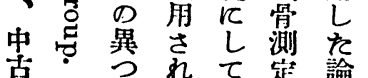

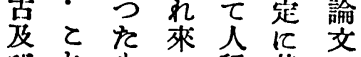

びれ \& つ 程基交二

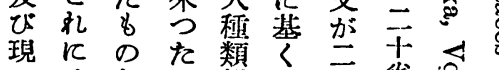

マはを似歌突

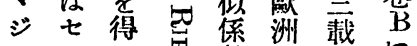

$+ル \tau$ 繁人

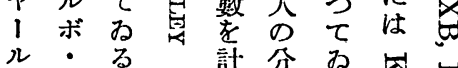

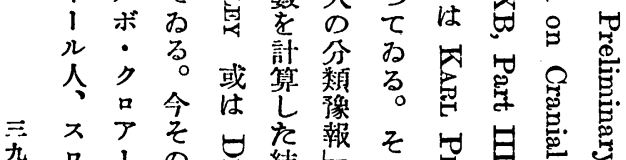

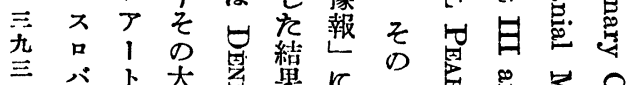

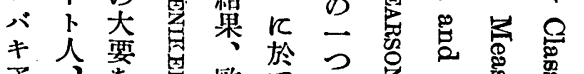

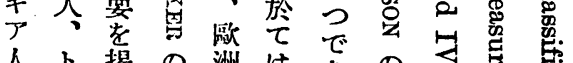

人ト揭の洲はであの危志

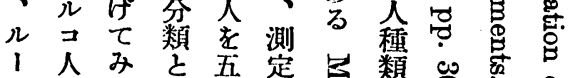

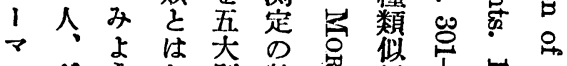

デ
く几あれ看其

が於るる取地

取る号が壳點

放發〈深附 泳

京热極之近意

自盛めの勝る

分ん他坂江

胃で重占式地

整聞各な㹂介爷

京し程邀㞣在尺

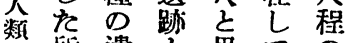

然所遗思て

著 管标跡洘尘: 所

言酎へれ明飞

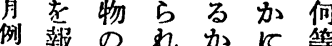

会告谈る れ陆設

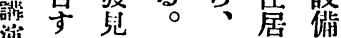

然るが私住址な

要。あの居のき

つ發址: 伏 雐

た挶の在の

や後重茂痕

飞同橉 知 跡

闑地名台范 